\title{
Recurrent respiratory papillomatosis causing chronic stridor and delayed speech in an 18-month-old boy
}

\author{
Adel Alharbi $M D^{1}$, Derek Drummond $M^{2}{ }^{2}$, Alfredo Pinto $M^{3}{ }^{3}$, Valerie Kirk MD FRCPC ${ }^{1}$
}

\begin{abstract}
A Alharbi, D Drummond, A Pinto, V Kirk. Recurrent respiratory papillomatosis causing chronic stridor and delayed speech in an 18-month-old boy. Can Respir J 2006;13(7):381-383.
\end{abstract}

\begin{abstract}
Recurrent respiratory papillomatosis is a relatively uncommon disease that presents clinically with symptoms ranging from hoarseness to severe dyspnea. Human papilloma virus types 6 and 11 are important in the etiology of papillomas and are most probably transmitted from mother to child during birth. Although spontaneous remission is frequent, pulmonary spread and/or malignant transformation resulting in death has been reported. $\mathrm{CO}_{2}$ laser evaporation of papillomas and adjuvant drug therapy using lymphoblastoid interferon-alpha are the most common treatments. However, several other treatments have been tried, with varying success. In the present report, a case of laryngeal papillomatosis presenting with chronic stridor and delayed speech is described.
\end{abstract}

Key Words: Human papilloma virus; Pediatric laryngeal disease; Recurrent respiratory papillomatosis

\section{CASE PRESENTATION}

An 18-month-old boy was referred to the pulmonary service at the Alberta Children's Hospital in Calgary from the emergency department with a history of noisy breathing since birth. He was accompanied by his father, who reported noisy breathing that was primarily inspiratory in nature and present continuously, but worsened with upper respiratory tract infections. There was no diurnal or positional variation noted. Accompanying symptoms included marked hoarseness, a very weak cry and a significant delay in speech development. Detailed sleep and feeding histories revealed no additional pertinent information. The boy was born via spontaneous vaginal delivery at term following an uneventful pregnancy. There was no available information regarding maternal history of genital human papilloma virus (HPV) infection. There was no history of prior hospital admission; however, there were frequent visits to doctors' offices for evaluation of the stridor. Previous clinical diagnoses included asthma and laryngomalacia. Family history was noncontributory. On physical examination, the boy had no signs of respiratory distress at rest. Mild, persistent inspiratory stridor was noted, as well as an almost absent voice. There were no dysmorphic features and his weight was $10 \mathrm{~kg}$ (within the third to 10th percentile). His vital signs, including oxygen saturation, were within normal limits at rest. Chest examination was unremarkable with respect to inspection and

\section{Une papillomatose respiratoire récurrente responsable d'un stridor et d'un retard de langage chez un bébé de 18 mois}

La papillomatose respiratoire récurrente est une maladie relativement peu fréquente, qui se manifeste cliniquement par des symptômes allant d'un enrouement à une dyspnée grave. Les papillomavirus de types 6 et 11 occupent une grande place dans l'étiologie des papillomes et sont probablement transmis de la mère à l'enfant pendant l'accouchement. La rémission spontanée est fréquente, mais on a déjà déclaré des cas de propagation pulmonaire ou de transformation maligne à l'issue fatale. Les traitements les plus courants sont le laser au gaz carbonique des papillomes et une chimiothérapie adjuvante au moyen d'interféron alpha lymphoblastoïde. Cependant, on a tenté plusieurs autres traitements, avec des résultats variés. Dans le présent rapport, on décrit un cas de papillomatose laryngée se manifestant par un stridor chronique et un retard de langage.

\footnotetext{
${ }^{1}$ Department of Paediatrics, Division of Respiratory Medicine; ${ }^{2}$ Department of Paediatric General Surgery, Division of Otolaryngology; ${ }^{3}$ Department of Pathology, University of Calgary, Calgary, Alberta

Correspondence: Dr Valerie Kirk, 1820 Richmond Road Southwest, Calgary, Alberta T2T 5C7. Telephone 403-943-2923, fax 403-943-7059, e-mailval.kirk@calgaryhealthregion.ca
} 


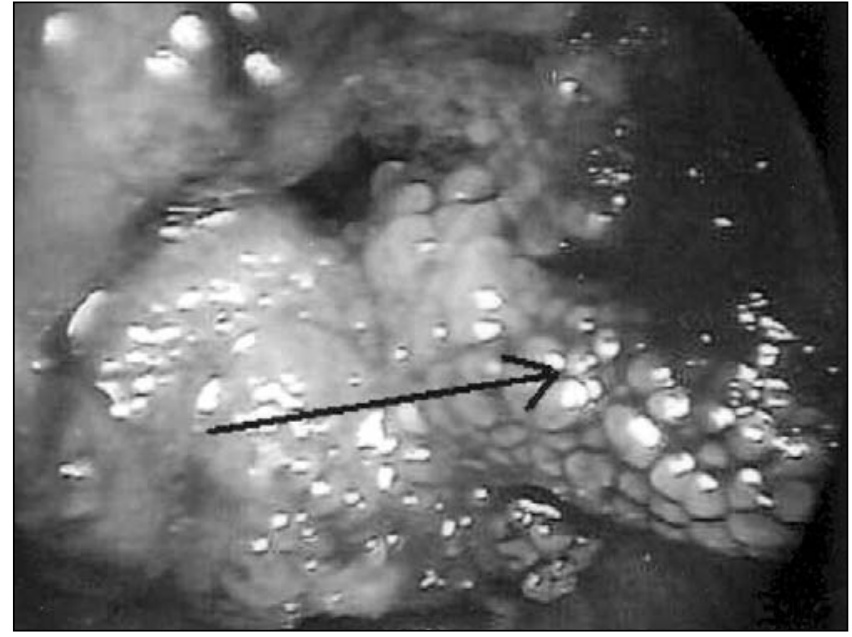

Figure 1) Bronchoscopic picture showing extensive papillomas involving the larynx mainly at the true vocal folds

\section{DISCUSSION}

Recurrent respiratory papillomatosis (RRP) is a relatively uncommon, nonmalignant yet aggressive disease that is characterized by papillomas present at various sites in the respiratory tract. Despite therapeutic measures and sometimes numerous surgical procedures, recurrence is frequent.

The onset of RRP may occur during either childhood or adulthood, with a bimodal age distribution showing the first peak in children younger than five years of age and the second peak in patients between 20 and 30 years of age. The juvenileonset form of RRP is most common, with $25 \%$ of cases presenting during infancy (1). A classification system replacing the terms 'juvenile' and 'adult' with 'aggressive' and 'nonaggressive' was proposed by Doyle et al (2), and is probably more appropriate for clinical use because disease in the very youngest of patients is typically more aggressive than that seen in the older population. A national survey of both pediatric and general otolaryngologists reported an estimated 2354 new cases of pediatric RRP in the United States every year (incidence of 4.3 per 100,000) (1).

HPV DNA was first isolated in papillomas of the larynx from patients with both juvenile- and adult-onset RRP in 1982 (3). It was described as a naked, double-stranded, icosahedrally shaped virus with circular supercoiled DNA belonging to the papovavirus family (3). There are 90 subtypes of HPV known with only two subtypes responsible for most clinical cases of RRP (subtypes 6 and 11). These subtypes are also responsible for condyloma acuminata (genital warts), while subtypes 16 and 18 have been implicated as causative in cancer, particularly cancer of the uterine cervix (4). Transmission of HPV in RRP is thought to be multifactorial. However, in children, transmission most often occurs vertically due to active maternal HPV infection at the time of delivery (4). Other postulated routes include hematogenous spread and ascending transplacental inoculation (4). Mothers of affected children can recall by history active or prior HPV infection approximately $50 \%$ of the time. It has been estimated that $10 \%$ to $25 \%$ of women of childbearing age have latent or active HPV in cervical swabs (4). HPV DNA has been isolated in one-third to one-half of aerodigestive tract swabs of children born to affected mothers; however, the majority of these children do not develop disease. The risk of developing disease in this

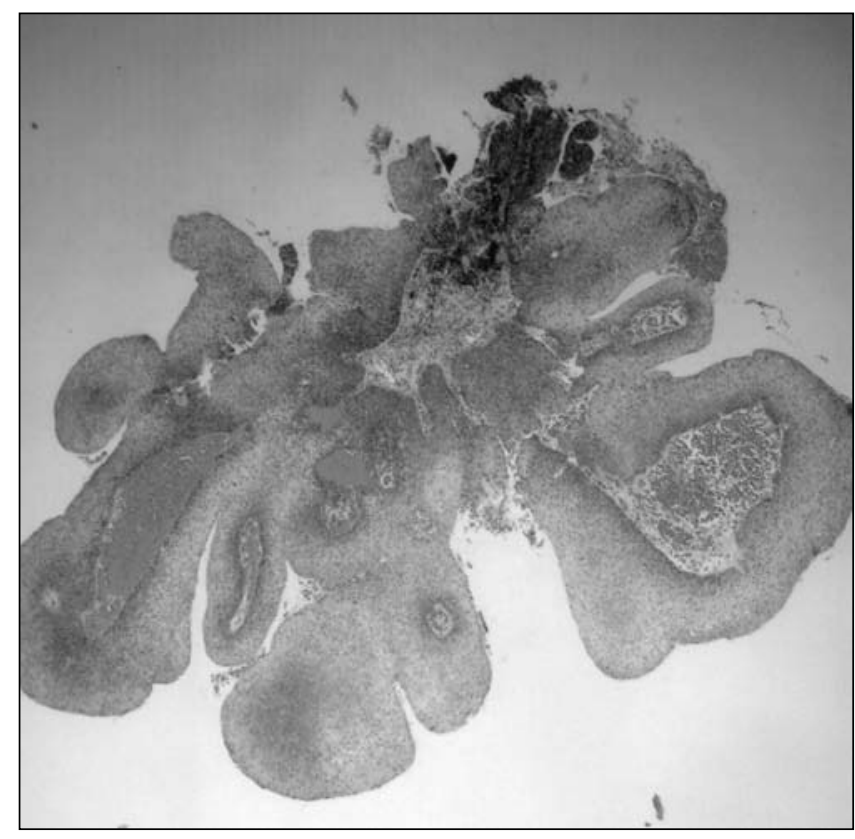

Figure 2) Histological sections show a squamous cell papilloma with finger-like projections (hematoxylin stain, original magnification $\times 40$ )

population is not precisely known but has been estimated to be one in 400 (5). The current medical literature generally does not support routine prophylactic Caesarian sections in women with HPV-positive swabs in the absence of other indications (5). However, in one study, only one of 109 children with RRP had a history of Caesarian birth, a rate much lower than that of the general population (5).

The most common presentation of RRP is hoarseness. Young children may also present with a weak cry, chronic cough, stridor or even complete aphonia $(1,4)$. Distal disease can develop and portends a poorer prognosis due to its inaccessibility. Patients may also develop cavitary pulmonary lesions, which can lead to atelectasis, chronic infection, postobstructive pneumonia and sepsis (6). It appears that distal disease is more common with HPV type 11 infection (6). The lesions rarely undergo malignant degeneration, which is almost uniformly fatal (1).

Although the HPV lesions can be found anywhere in the aerodigestive tract, there appears to be a predilection for areas where there is a junction of squamous and ciliary epithelium. These areas include the limen vestibuli (junction of the nasal vestibule and the nasal cavity proper), the nasopharyngeal surface of the soft palate, the midzone of the laryngeal surface of the epiglottis, the upper and lower margins of the ventricle, the undersurface of the vocal folds, and the carinal and bronchial spurs (7). The diagnosis is usually confirmed by direct inspection and histological findings on biopsy specimens. The clinical finding on direct laryngoscopy is a verrucous outgrowth. Histologically, an epithelial projection with a fibrovascular core is seen with associated parakeratosis, koilocytosis and acanthosis (4).

Despite advances in medical therapy, surgery remains the primary treatment for RRP. The goal of surgery is the removal of as much disease as possible without damaging the adjacent or underlying tissue, which can lead to scarring, stenosis and loss of function (4). In an attempt to minimize the untoward 
effects of surgery, various techniques and instrumentation have been described. These include endoscopic debulking with laryngeal forceps or microdebriders, excision with cold phonomicrosurgical instruments, and a combination of excision and ablation with the $\mathrm{CO}_{2}$ laser (8). While there are advocates for each technique, the $\mathrm{CO}_{2}$ laser and the laryngeal microdebrider are currently the most widely used (8).

While numerous adjuvant medical therapies have shown promise in the past, none have demonstrated a lasting or curative effect, and many have unfavourable side effects or toxicity profiles. These include interferon-alpha $2 \mathrm{a}$, retinoic acid, indole-3-carbinol, and photodynamic therapy with dihematoporphyrin (1). More recently, the antiviral drug cidofovir has demonstrated efficacy against RRP and is considered a promising new adjuvant in the management of this disease. Cidofovir is an acyclic nucleoside phosphonate that has antiviral activity against a wide range of DNA viruses, including HPV. It exerts

\section{REFERENCES}

1. Wiatrak BJ. Overview of recurrent respiratory papillomatosis. Curr Opin Otolaryngol Head Neck Surg 2003;11:433-41.

2. Doyle DJ, Gianoli GJ, Espinola T, Miller RH. Recurrent respiratory papillomatosis: Juvenile versus adult forms. Laryngoscope 1994;104:523-7.

3. Gissmann L, Diehl V, Schultz-Coulon HJ, zur Hausen H. Molecular cloning and characterization of human papilloma virus DNA derived from a laryngeal papilloma. J Virol 1982;44:393-400.

4. Derkay CS. Recurrent respiratory papillomatosis. Laryngoscope 2001;111:57-69.

5. Shah K, Kashima H, Polk BF, Shah F, Abbey H, Abramson A. Rarity of cesarean delivery in cases of juvenile-onset respiratory papillomatosis. Obstet Gynecol 1986;68:795-9.

6. Zawadzka-Glos L, Jakubowska A, Chmielik M, et al. Lower airway its effect through selective inhibition of viral DNA polymerases during viral replication. Cidofovir has been approved by the Food and Drug Administration for the treatment of cytomegalovirus retinitis in HIV patients at an intravenous dose of $5 \mathrm{mg} / \mathrm{kg}$. When used intravenously at this dose, cidofovir can cause nephrotoxicity and neutropenia (9). However, recent studies suggest that these side effects are limited to intravenous use, with no evidence of renal, hepatic or hematological toxicity when injected into papillomatous lesions of the larynx or trachea (10).

\section{CONCLUSIONS}

RRP is caused by HPV subtypes 6 and 11. It affects people of all ages, but tends to be more aggressive in the young. Lifethreatening airway obstruction may develop. The natural history is variable and poorly understood. Treatment is essentially palliative with surgical debulking.

papillomatosis in children. Int J Pediatr Otorhinolaryngol 2003;67:1117-21.

7. Kashima H, Mounts P, Leventhal B, Hruban RH. Sites of predilection in recurrent respiratory papillomatosis. Ann Otol Rhinol Laryngol 1993;102:580-3.

8. Peyton Shirley W, Wiatrak B. Is cidofovir a useful adjunctive therapy for recurrent respiratory papillomatosis in children? Int J Pediatr Otorhinolaryngol 2004;68:413-8.

9. Silverman DA, Pitman MJ. Current diagnostic and management trends for recurrent respiratory papillomatosis. Curr Opin Otolaryngol Head Neck Surg 2004;12:532-7.

10. Pransky SM, Albright JT, Magit AE. Long-term follow-up of pediatric recurrent respiratory papillomatosis managed with intralesional cidofovir. Laryngoscope 2003;113:1583-7. 


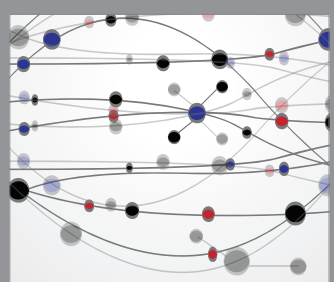

The Scientific World Journal
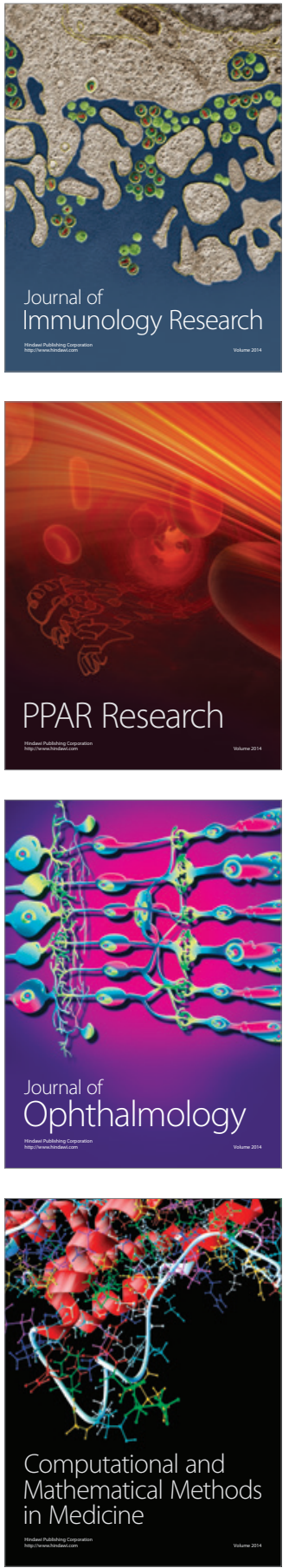

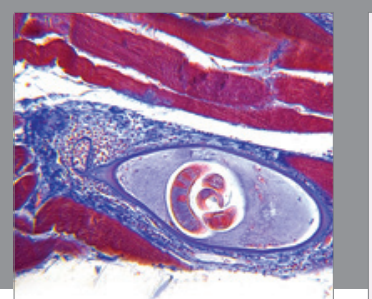

Gastroenterology Research and Practice

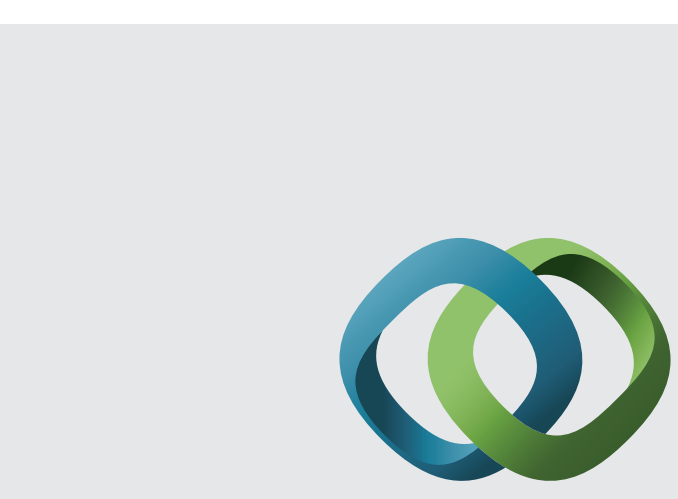

\section{Hindawi}

Submit your manuscripts at

http://www.hindawi.com
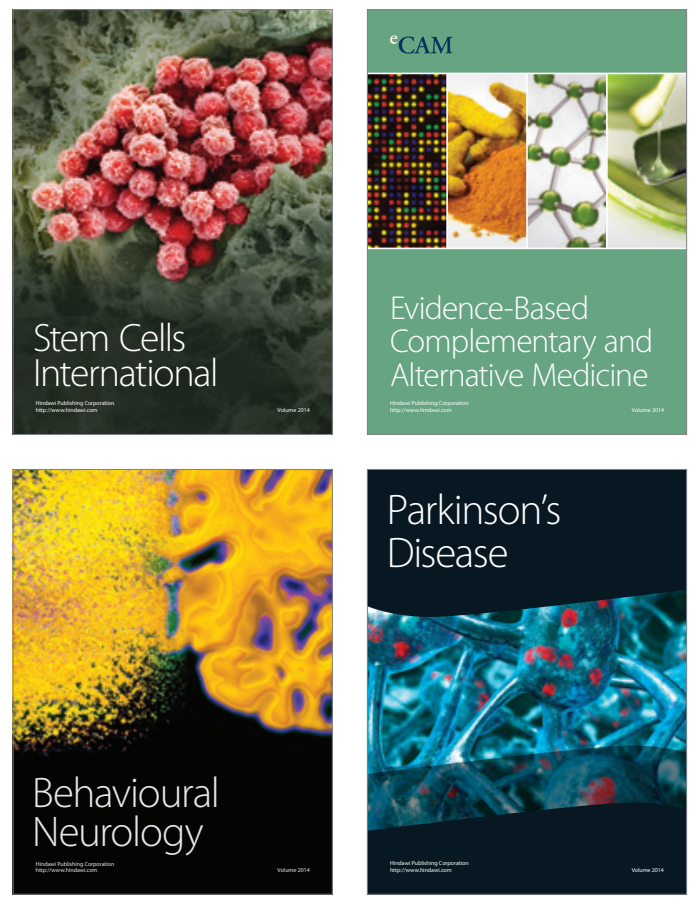
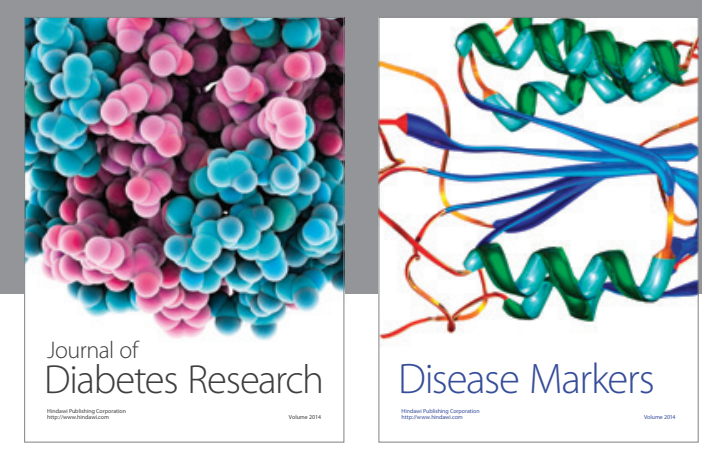

Disease Markers
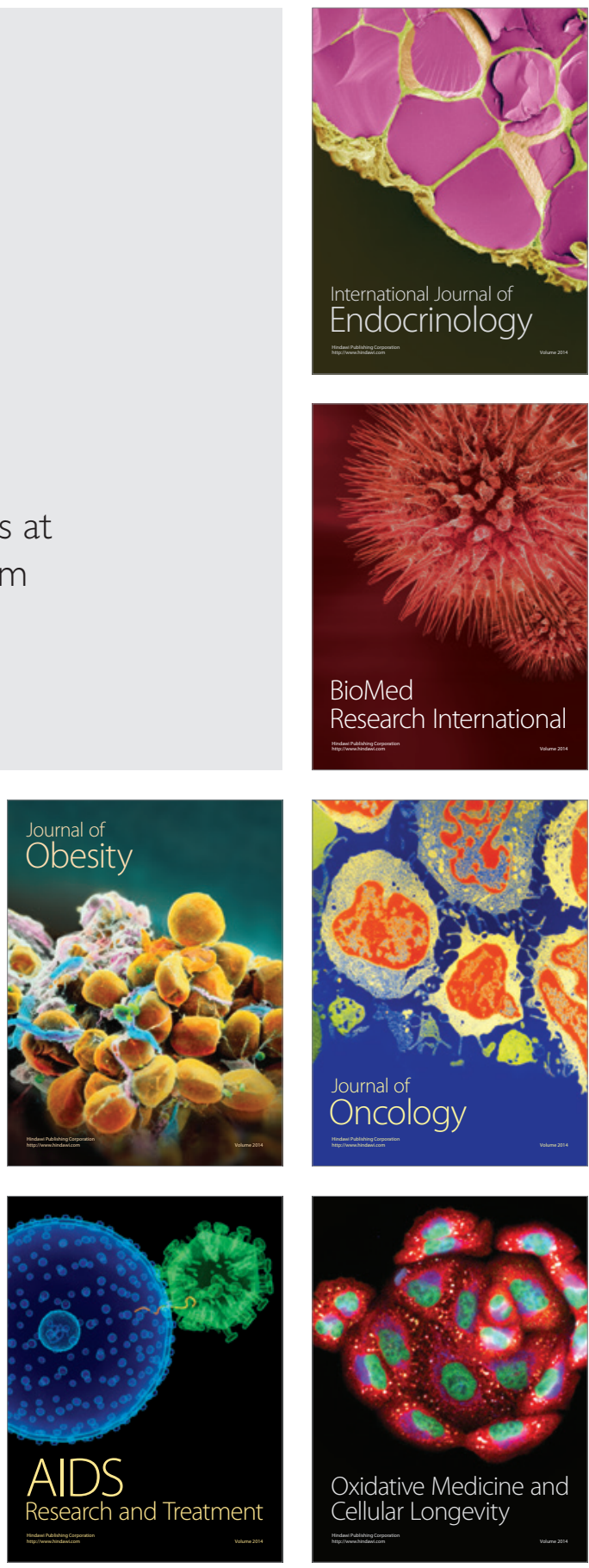